\title{
Cardiac arrest associated with carbon dioxide gas embolism during laparoscopic surgery for colorectal cancer and liver metastasis
} -A case report-

\author{
Il-Seok Kim, Jae-Woo Jung, and Keun-Man Shin
}

Department of Anesthesiology and Pain Medicine, Kangdong Sacred Heart Hospital, Hallym University College of Medicine, Seoul, Korea

Clinically apparent carbon dioxide $\left(\mathrm{CO}_{2}\right)$ gas embolism is uncommon, but it may be a potentially lethal complication if it occurs. We describe a 40 -year-old woman who suffered a $\mathrm{CO}_{2}$ gas embolism with cardiac arrest during laparoscopic surgery for colorectal cancer and liver metastasis. Intra-abdominal pressure was controlled to less than $15 \mathrm{mmHg}$ during $\mathrm{CO}_{2}$ gas pneumoperitoneum. The right hepatic vein was accidentally disrupted during liver dissection, and an emergent laparotomy was performed. A few minutes later, the end-tidal $\mathrm{CO}_{2}$ decreased, followed by bradycardia and pulseless electrical activity. External cardiac massage, epinephrine, and atropine were given promptly. Ventilation with $100 \%$ oxygen was started and the patient was moved to the Trendelenburg position. Two minutes after resuscitation was begun, a cardiac rhythm reappeared and a pulsatile arterial waveform was displayed. A transesophageal echocardiogram showed air bubbles in the right pulmonary artery. The patient recovered completely, with no cardiopulmonary or neurological sequelae. (Korean J Anesthesiol 2012; 63: 469-472)

Key Words: Carbon dioxide gas embolism, Laparoscopic surgery, Transesophageal echocardiography.

Laparoscopic surgery is a popular alternative to open procedures with a number of advantages for the patient. These include reduced pain due to smaller incisions and hemorrhaging, and shorter recovery time. However, rare complications have been reported, including puncture of hollow viscera and major vessels, hemorrhage, pneumomediastinum, pneumothorax, subcutaneous emphysema, and massive gas embolism [1]. Carbon dioxide $\left(\mathrm{CO}_{2}\right)$ is the most commonly used gas for creating a pneumoperitoneum. It is inexpensive, highly soluble in blood, rapidly eliminated, and noncombustible. Subclinical $\mathrm{CO}_{2}$ gas embolism with minimal cardiopulmonary instability detected by transesophageal echocardiography (TEE) commonly occurs during laparoscopic surgery [2,3]. Clinically apparent $\mathrm{CO}_{2}$ gas embolism is a rare but potentially lethal com-

Received: October 31, 2011. Revised: November 28, 2011. Accepted: December 2, 2011.

Corresponding author: Il-Seok Kim, M.D., Department of Anesthesiology and Pain Medicine, Kangdong Sacred Heart Hospital, Hallym University College of Medicine, 445, Gil-dong, Gangdong-gu, Seoul 134-010, Korea. Tel: 82-2-2224-2659, Fax: 82-2-474-0956, E-mail: gns70@hallym.or.kr C) This is an open-access article distributed under the terms of the Creative Commons Attribution Non-Commercial License (http:// creativecommons.org/licenses/by-nc/3.0/), which permits unrestricted non-commercial use, distribution, and reproduction in any medium, provided the original work is properly cited. 
plication of laparoscopic surgery [4-6]. We experienced a case of cardiac arrest associated with $\mathrm{CO}_{2}$ gas embolism due to rupture of the hepatic vein during laparoscopic surgery for colorectal cancer and liver metastasis. We resuscitated promptly and diagnosed $\mathrm{CO}_{2}$ gas embolism with TEE. The patient recovered without cardiopulmonary or neurological sequelae.

\section{Case Report}

A 40-year-old woman (height $157.8 \mathrm{~cm}$, weight $46.8 \mathrm{~kg}$ ) was scheduled for a laparoscopic low anterior resection (LAR) and hepatic tumorectomy due to colorectal cancer with liver metastasis. The patient had a history of paroxysmal supraventricular tachycardia which was controlled by medication with verapamil $180 \mathrm{mg}$ daily. A week before the surgery, she had undergone a radiofrequency catheter ablation for paroxysmal supraventricular tachycardia. A follow-up electrocardiography (ECG) showed normal sinus rhythm, and transthoracic echocardiography showed normal chamber size, normal left ventricular wall thickness, and normal left ventricular ejection fraction without regional wall motion abnormalities. Laboratory studies were unremarkable.

The patient received glycopyrrolate $0.2 \mathrm{mg}$ intramuscularly as premedication 30 minutes before surgery. Monitoring included non-invasive blood pressure determination, ECG (lead II), pulse oximetry, and end-tidal $\mathrm{CO}_{2}$ concentration $\left(\mathrm{E}_{\mathrm{T}} \mathrm{CO}_{2}\right)$ measurements. Vital signs included a blood pressure (BP) of 125/80 mmHg, a heart rate (HR) of 82 beats/min with regular sinus rhythm, and peripheral oxygen saturation $\left(\mathrm{SpO}_{2}\right)$ of $98 \%$. Anesthesia was induced using mask administration of $100 \% \mathrm{O}_{2} .2 \%$ lidocaine $30 \mathrm{mg}$, propofol $100 \mathrm{mg}$ and rocuronium $40 \mathrm{mg}$ were administered intravenously, and the trachea was intubated using a $7.0 \mathrm{~mm}$ cuffed endotracheal tube. Anesthesia was maintained using $2 \mathrm{~L} / \mathrm{min} \mathrm{O}_{2}, 2 \mathrm{~L} / \mathrm{min}$ nitrous oxide $\left(\mathrm{N}_{2} \mathrm{O}\right)$, and 1.5-2.0 vol\% sevoflurane. Ventilation was mechanically performed with a tidal volume of $500 \mathrm{ml}$ and a rate of $10 \mathrm{breaths} / \mathrm{min}$. The right radial artery was cannulated for continuous monitoring and a central venous catheter was placed in the right internal jugular vein to be prepared for massive bleeding.

The operative technique involved intraperitoneal insufflation of $\mathrm{CO}_{2}$ via a Veress needle inserted through a small infraumbilical incision. Pneumoperitoneum was maintained with a variable-flow insufflator at a pressure of $15 \mathrm{mmHg}$ throughout surgery. $\mathrm{E}_{\mathrm{T}} \mathrm{CO}_{2}$ was kept within the range of 30-35 $\mathrm{mmHg}$ with a respiratory rate of 15 breaths/min, a tidal volume of $450 \mathrm{ml}$, and an inspiration: expiration ratio of $1: 1.5$. The patient was placed in the Trendelenburg position during the LAR. Vital signs were stable, and the duration of the operation was 190 minutes.
After the LAR, hepatic tumorectomy was performed in the reverse Trendelenburg and left lateral position. Twenty minutes after changing the position, $\mathrm{E}_{\mathrm{T}} \mathrm{CO}_{2}$ increased to $48 \mathrm{mmHg}$. Assuming $\mathrm{CO}_{2}$ absorption, ventilation was converted to a rate of $18 \mathrm{breaths} / \mathrm{min}$ and a tidal volume of $400 \mathrm{ml}$. Peak airway pressure did not exceed $25 \mathrm{mmHg}$. Ten minutes after changing the ventilator settings, $\mathrm{E}_{\mathrm{T}} \mathrm{CO}_{2}$ decreased to $32 \mathrm{mmHg}$ and the vital signs were stable.

Fifty minutes later, the right hepatic vein was accidentally disrupted during liver dissection. Laparoscopic ligation was impossible because the hepatic vein was not compressed. An emergent laparotomy to control bleeding was immediately performed in the neutral position. A few minutes later, systolic arterial pressure decreased from 110 to $62 \mathrm{mmHg}$. We accelerated the infusion rate of Hartmann's solution, and $10 \mathrm{mg}$ ephedrine was administered intravenously. However, the vital signs deteriorated. Arterial blood gas analysis showed $\mathrm{pH}$ 6.994, $\mathrm{PaCO}_{2} 106 \mathrm{mmHg}$, $\mathrm{PaO}_{2} 259 \mathrm{mmHg}, \mathrm{HCO}_{3}{ }^{-} 24.4 \mathrm{mEq} / \mathrm{L}, \mathrm{SaO}_{2} 98.3 \%\left(\mathrm{FiO}_{2}: 0.5\right)$, hemoglobin $9.4 \mathrm{~g} / \mathrm{dL}$ and hematocrit $29 \%$. The waveform of the capnogram suddenly decreased, and progressive arterial desaturation developed. This was followed by bradycardia (HR $=30-40$ beats $/ \mathrm{min}$ ) and the pulsatile activity disappeared from the arterial line. External cardiac massage, epinephrine (two doses of $1 \mathrm{mg}$ ) and atropine (one dose of $0.5 \mathrm{mg}$ ) were given. At the same time, ventilation with $100 \% \mathrm{O}_{2}$ was begun and the patient was moved to the Trendelenburg position because pulmonary gas embolism was strongly suspected. Two minutes after initiation of cardiac massage, a cardiac rhythm reappeared and a pulsatile arterial waveform was displayed dramatically. A TEE was performed, and it showed air bubbles

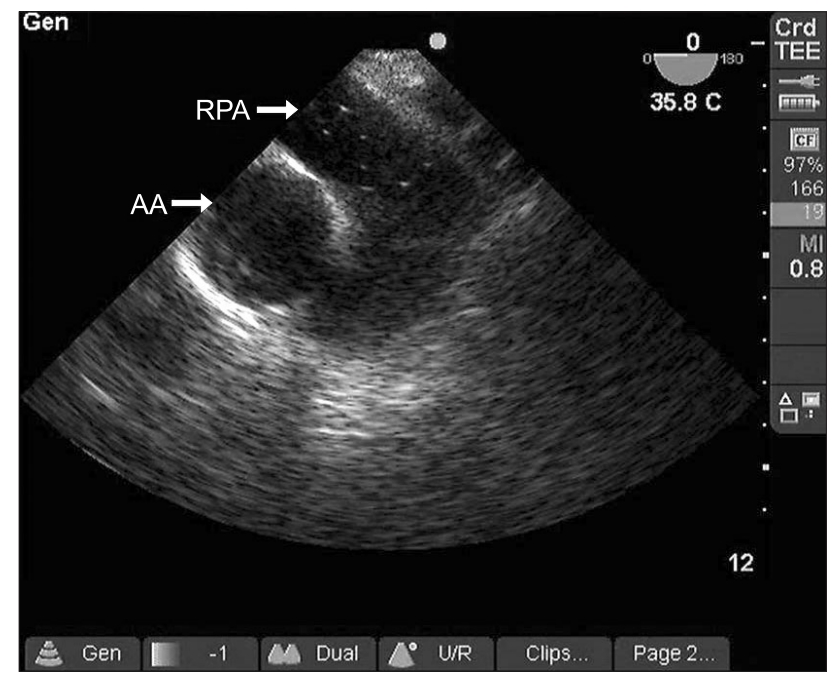

Fig. 1. Carbon dioxide gas embolism detected by transesophageal echocardiography. Air bubbles are seen in the right pulmonary artery on a mid-esophageal ascending aortic short axis view. AA: ascending aorta, RPA: right pulmonary artery. 
in the right pulmonary artery on a mid-esophageal ascending aortic short axis view (Fig. 1). At that time, we decreased the infusion of intravenous solution in order to avoid the formation of an echocardiographic contrast caused by rapid intravenous infusion. However, a mid-esophageal four chamber view showed no residual presence of air bubbles, a normal right ventricle without septal shift, and non-compression of the left ventricle. Fifteen minutes after cardiopulmonary resuscitation, arterial blood gas analysis showed $\mathrm{pH} 7.280, \mathrm{PaCO}_{2} 34 \mathrm{mmHg}$, $\mathrm{PaO}_{2} 499 \mathrm{mmHg}, \mathrm{HCO}_{3}{ }^{-} 15.4 \mathrm{mEq} / \mathrm{L}, \mathrm{SaO}_{2} 99.2 \%\left(\mathrm{FiO}_{2}: 1.0\right)$, hemoglobin $6.9 \mathrm{~g} / \mathrm{dl}$ and hematocrit $22 \%$. The patient received 2 units of packed red blood cells.

The operation was completed using an open approach without any additional major problems. The patient was transferred to the intensive care unit and recovered consciousness 20 minutes later. She was extubated 2 hours later and experienced no cardiopulmonary or neurological sequelae.

\section{Discussion}

Current investigations using TEE indicate that subclinical $\mathrm{CO}_{2}$ gas embolism is not uncommon during laparoscopic surgery $[2,3]$. Gas embolism is shown to occur during two distinct periods: first, during peritoneal insufflation, and second, during gallbladder or liver dissection. During peritoneal insufflation, the gas may enter the venous circulation accidentally via a small tear in a blood vessel from the abdominal wall or just below the peritoneal surface after the introduction of a trocar or Veress needle. A necessary condition for gas embolism is the presence of an open vein, with a lower pressure in the vein than the surrounding pressure. Fortunately, the increased intra-abdominal pressure collapses the injured vessels and terminates the embolic events. Cardiopulmonary instability is not common in this period. The surgeon selects the pressure in the abdomen desired for surgical exposure as well as the maximal flow rate for insufflation. The machine stops the insufflation periodically and measures the intra-abdominal pressure. A slow flow rate reduces the severity of gas embolism if inadvertent intravascular injection occurs.

During gallbladder or liver dissection, blood vessels exposed at the surface of the liver may be kept open by the solid surrounding parenchyma, and this, along with a longer period of positive intra-abdominal pressure than the peritoneal insufflation period, produces favorable conditions for $\mathrm{CO}_{2}$ gas embolism. Moreover, the intrahepatic veins are thin-walled and anatomically difficult to collapse [7]. In our case, it seemed that a massive amount of $\mathrm{CO}_{2}$ gas entered directly into a ruptured hepatic vein.

Hemodynamic effects in laparoscopic surgery are predominantly due to hypercarbia and the increased intra-abdominal pressure [8]. These effects are further influenced by the patient's position, duration of the procedure, rate of administration and volume of gas used for insufflation, age of the patient, and combined cardiopulmonary conditions [9,10]. During abdominal procedures, intra-abdominal pressure is not allowed to exceed $15 \mathrm{mmHg}[1,8]$. Higher pressures are associated with faster $\mathrm{CO}_{2}$ absorption and gas embolism. Intra-abdominal pressure of approximately $14 \mathrm{mmHg}$ produces significant increases in HR, mean arterial pressure, and systemic vascular resistance, but decreases in venous return. Stroke volume falls, but cardiac output is maintained by compensatory tachycardia. These effects are exaggerated by the head-up position. When intra-abdominal pressure is approximately $20 \mathrm{mmHg}$, similar effects are seen and cardiac output is maintained. However, at an intra-abdominal pressure of approximately $30 \mathrm{mmHg}$, central venous pressure falls significantly. Trendelenburg position may not overcome the decrease in venous return and cardiac output, presumably because of high pressure on the inferior vena cava. Cardiac index falls to $50 \%$ of the preoperative value in 5 minutes. Intra-abdominal pressure of approximately $40 \mathrm{mmHg}$ decreases cardiac output by $17 \%$ and $53 \%$ in normovolemic and hypovolemic patients, respectively. Venous return and right heart filling pressure decrease significantly.

Although not routinely used, TEE is the most sensitive method for diagnosis of gas embolism $[11,12]$. Changes in $\mathrm{E}_{\mathrm{T}} \mathrm{CO}_{2}$, pulmonary artery pressure, and precordial Doppler are less sensitive. Using TEE, air bubbles are seen in the right atrium, the right ventricle, the pulmonary artery, or the inferior vena cava. A massive gas embolism with "gas lock" in the right atrium and pulmonary artery can lead to right ventricular failure and show an interventricular septal shift toward the left ventricle and a decrease in left ventricular dimensions [13]. Gas emboli are able to escape from the right atrium to the left atrium through an open foramen ovale in positive pressure ventilation and induce a paradoxical air embolism [14].

During laparoscopy, monitoring of $\mathrm{E}_{\mathrm{T}} \mathrm{CO}_{2}$ is essential, as it may help in the early detection of venous $\mathrm{CO}_{2}$ embolism [15]. A transient but rapid rise in $\mathrm{E}_{\mathrm{T}} \mathrm{CO}_{2}$ has been suggested as a useful early sign of venous $\mathrm{CO}_{2}$ embolism. When the $\mathrm{CO}_{2}$ embolism is large enough to cause pulmonary outflow obstruction, it leads to decreased cardiac output and $\mathrm{E}_{\mathrm{T}} \mathrm{CO}_{2}$.

In our case, it seemed that a massive amount of $\mathrm{CO}_{2}$ gas directly entered into a ruptured hepatic vein and acted as a gas lock in the pulmonary outflow tract that led to right ventricular failure. This effect was manifested as a sudden decrease in $\mathrm{E}_{\mathrm{T}} \mathrm{CO}_{2}$ and cardiac arrest. After resuscitation, TEE was performed to search for the etiology of the event. The procedure showed air bubbles in the right pulmonary artery on a mid-esophageal ascending aortic short axis view. The massive air embolism could be broken by external cardiac massage, and remnant $\mathrm{CO}_{2}$ 
gas was seen in the right pulmonary artery. Absorbed $\mathrm{CO}_{2}$ is highly soluble in blood, so it rapidly distributed to the tissues. This resulted in no cardiopulmonary or neurological sequelae.

$\mathrm{N}_{2} \mathrm{O}$ can move into closed gas spaces. The use of $\mathrm{N}_{2} \mathrm{O}$ for anesthesia may expand the volume of a gas embolus in cases in which air inadvertently enters the bloodstream. Therefore, the use of $\mathrm{N}_{2} \mathrm{O}$ is not recommended in laparoscopic surgery, considering the possibility of accidental $\mathrm{CO}_{2}$ gas embolism.

TEE is used in all open heart surgical procedures. It should also be used as a rescue tool for unexplained life-threatening circulatory instability in non-cardiac surgery. We used TEE for detection of gas embolism.

If a gas embolism is suspected, a series of measures have to be performed. Immediately stop $\mathrm{CO}_{2}$ insufflation, deflate the pneumoperitoneum, hyperventilate the patient with $100 \%$ $\mathrm{O}_{2}$, and place the patient in Trendelenburg position or the left lateral decubitus with head down position, which allows the gas to rise into the apex of the right ventricle and prevents its entry into the pulmonary artery. Administration of vasopressors and inotropic agents to maintain cardiac output is necessary in cases of hemodynamic instability. Cardiopulmonary bypass has been used for refractive hemodynamic instability.

We experienced a case of cardiac arrest associated with $\mathrm{CO}_{2}$ gas embolism due to rupture of the hepatic vein during laparoscopic surgery for colorectal cancer and liver metastasis. We resuscitated promptly and diagnosed $\mathrm{CO}_{2}$ gas embolism with TEE. The patient recovered without cardiopulmonary or neurological sequelae.

In conclusion, catastrophic $\mathrm{CO}_{2}$ gas embolism can occur when laparoscopic surgery is performed close to large veins, and caution should be exerted with these patients. Careful monitoring, such as the use of TEE, is essential to allow early detection of gas embolism. Increasing awareness and practicing vigilance can significantly reduce morbidity and mortality from $\mathrm{CO}_{2}$ gas embolism.

\section{References}

1. Gutt CN, Oniu T, Mehrabi A, Schemmer P, Kashfi A, Kraus T, et al. Circulatory and respiratory complications of carbon dioxide insufflation. Dig Surg 2004; 21: 95-105.

2. Derouin M, Couture P, Boudreault D, Girard D, Gravel D. Detection of gas embolism by transesophageal echocardiography during laparoscopic cholecystectomy. Anesth Analg 1996; 82: 119-24.

3. Park CH, Lee JY, Kim YC, Kim SH, Jung KH, Kim MG, et al. Detection of carbon dioxide embolism using transesophageal echocardiography during thoracoscopic sympathicotomy. Korean J Anesthesiol 2006; 50: 173-8.

4. Kono M, Yahagi N, Kitahara M, Fujiwara Y, Sha M, Ohmura A. Cardiac arrest associated with use of an argon beam coagulator during laparoscopic cholecystectomy. Br J Anaesth 2001; 87: 644-6.

5. Haroun-Bizri S, ElRassi T. Successful resuscitation after catastrophic carbon dioxide embolism during laparoscopic cholecystectomy. Eur J Anaesthesiol 2001; 18: 118-21.

6. Shin WJ, Lee YM, Hahm KD, Jeong YB, Choi IC. Massive carbon dioxide embolism during the minimally invasive robot-assisted cardiac surgery. Korean J Anesthesiol 2006; 50: 99-102.

7. Hatano Y, Murakawa M, Segawa H, Nishida Y, Mori K. Venous air embolism during hepatic rescection. Anesthesiology 1990; 73: 1282-5.

8. Sharma KC, Brandstetter RD, Brensilver JM, Jung LD. Cardiopulmonary physiology and pathophysiology as a consequence of laparoscopic surgery. Chest 1996; 110: 810-5.

9. Hirvonen EA, Poikolainen EO, Pääkkönen ME, Nuutinen LS. The adverse hemodynamic effects of anesthesia, head-up tilt, and carbon dioxide pneumoperitoneum during laparoscopic cholecystectomy. Surg Endosc 2000; 14: 272-7.

10. Joris JL, Noirot DP, Legrand MJ, Jacquet NJ, Lamy ML. Hemodynamic changes during laparoscopic cholecystectomy. Anesth Analg 1993; 76: 1067-71.

11. Couture P, Boudreault D, Derouin M, Allard M, Lepage Y, Girard $D$, et al. Venous carbon dioxide embolism in pigs: an evaluation of end-tidal carbon dioxide, transesophageal echocardiography, pulmonary artery pressure, and precordial auscultation as monitoring modalities. Anesth Analg 1994; 79: 867-73.

12. Lee DC, Kil HK, Choi JS, Hong YW, Joo ST, Koo BN. The incidence of and severity of venous air embolism determined by transesophageal echocardiography in hepatic resection using a cavitron ultrasonic surgical aspirator. Korean J Anesthesiol 2004; 47: 64-8.

13. Martineau A, Arcand G, Couture P, Babin D, Perreault LP, Denault A. Transesophageal echocardiographic diagnosis of carbon dioxide embolism during minimally invasive saphenous vein harvesting and treatment with inhaled epoprostenol. Anesth Analg 2003; 96: 962-4.

14. Guggiari M, Lechat P, Garen-Colonne C, Fusciardi J, Viars P. Early detection of patent foramen ovale by two-dimensional contrast echocardiography for prevention of paradoxical air embolism during sitting position. Anesth Analg 1988; 67: 192-4.

15. Shulman D, Aronson HB. Capnography in the early diagnosis of carbon dioxide embolism during laparoscopy. Can Anaesth Soc J 1984; 31: 455-9. 